\title{
Camallanus cotti Fujita, 1927 (Nematoda, Camallanoidea) in ornamental aquarium fishes: pathology and morphology
}

\author{
Rodrigo Caldas Menezes*, Rogério Tortelly**, Roberto Tortelly-Neto***, Dely Noronha, \\ Roberto Magalhães Pinto/ ${ }^{+}++$
}

Laboratório de Helmintos Parasitos de Vertebrados, Departamento de Helmintologia, Instituto Oswaldo Cruz-Fiocruz, Av. Brasil 4365, 21040-900 Rio de Janeiro, RJ, Brasil *Centro de Criação de Animais de Laboratório-Fiocruz, Rio de Janeiro, RJ, Brasil

**Departamento de Patologia, Faculdade de Veterinária, Universidade Federal Fluminense, Niterói, RJ, Brasil ***Mestrado em CiênciasVeterinárias, Faculdade de Veterinária, Universidade Federal Fluminense, Niterói, RJ, Brasil

The pathology induced by the nematode Camallanus cotti in the aquarium fishes Beta splendens (beta fish) and Poecilia reticulata (guppy) consisted of gross and microscopic lesions, the former characterized by abdominal swelling with reddish parasites protruding from the anus in both fish hosts and the latter, similar in the beta fishes and guppies, by hemorrhage, congestion, edema, a few glandular elements, and extensive erosion areas in the rectum mucosa, with a marked thickening of the wall and absence of inflammatory infiltrate. Lesions were associated with the presence of several worms attached to the wall or free in the rectal lumen. This is the second reference of the parasite in Brazil and the first report of pathological findings related to this nematode species that is also briefly redescribed and illustrated for the first time on the basis of Brazilian samples.

Key words: nematodes - freshwater fishes - Camallanus cotti - pathology - Brazil

Ornamental fishes are of increasing economic importance worldwide taking into account the continuous trade involving several species that are either exported or imported from a couple of countries, mostly from Asia (Evans \& Lester 2001, Kim et al. 2005). The importation generally involves the introduction of exotic parasites that can affect a large number of hosts and the detection of parasitism is an important step to avoid the spreading of fish diseases among the native fauna.

This paper deals with the first data on the pathology induced by the exotic nematode Camallanus cotti Fujita, 1927 in two species of ornamental fishes kept in an aquarium in Niterói, state of Rio de Janeiro, Brazil; C. cotti is briefly redescribed and figured.

\section{MATERIALS AND METHODS}

Five adult guppies [Poecilia reticulata (Peters, 1859)] three males and two females and two adult females of the beta fish [Betta splendens (Regan, 1910)] were investigated for helminths. The fishes were kept in a home aquarium, for two months and had been purchased in a pet shop located in Niterói, state of Rio de Janeiro, Brazil. The guppies formerly derived from a fish farmer maintained in the state of São Paulo, Brazil. Fishes were necropsied in accordance with ethical procedures and dissected organs kept in Petri dishes with a $0.85 \% \mathrm{NaCl}$ solution for the recovery of worms under a stereoscope microscope.

\footnotetext{
${ }^{+}$Corresponding author: rmpinto@ioc.fiocruz.br

${ }^{++} \mathrm{CNPq}$ fellowship

Received 11 May 2006

Accepted 5 July 2006
}

Nematodes were fixed with steaming AFA $\left(70^{\circ} \mathrm{GL}\right.$ ethanol, 93\%; formaldehyde, 5\%; glacial acetic acid, 2\%) and stored as wet material in the same solution; some were further dehydrated in an ethanol series, clarified in glacial acetic acid, phenol and preserved as whole mounts in beechwood creosote and Canada balsam. A couple of parasites were stained with alcoholic chloride Langeron's carmine. Samples are deposited in the Helminthological Collection of the Oswaldo Cruz Institute (CHIOC). Portions of the parasitized intestines were removed and immediately fixed in $10 \%$ formalin, to be further routinely processed for paraffin embedding. Five micrometers thick sections were stained with hematoxylin and eosin (HE).

"En face" jelly mounts of the nematodes were obtained in accordance with the method of Anderson (1958) and photomicrographs in a Zeiss Axiophot bright-field microscope with a Differential Interference Contrast (DIC) apparatus and in a Leica stereomicroscope (live parasites). Identification of the nematodes was based on data after Moravec and Nagasawa (1989). Measurements are in millimeters $(\mathrm{mm})$ and means in parentheses.

\section{RESULTS}

Three of the five guppies and the two beta fishes examined were positive for nematodes.

On what concerns clinical signs, fishes were apathetic and, in the male guppies, a reduction of the libido was observed. Two guppy and two beta fish females presented abdominal swelling with reddish parasites protruding from the anus (Fig. 1); beta fish females also showed anorexia. Microscopic lesions were similar in both fish species and consisted of hemorrhage, congestion, edema, a few glandular elements, and extensive erosion areas in the rectum mucosa, with a marked thickening of the wall and absence of inflammatory infiltrate. Lesions were associated with the presence of several worms attached to the wall or free in the rectal lumen (Figs 2-5). 


\section{Camallanus cotti Fujita, 1927}

(Figs 6-10)

Redescription based on five adult males and five adult females.

Males - Total length 3,440-4,240 (3,901), maximum width 0.171-0.220 (0.195). Buccal capsule 0.083-0.100 (0.093) long, 0.076-0.102 (0.091) wide, including ring at base 0.005-0.009 (0.009) long, 0.058-0.069 (0.063) wide. Buccal capsule with about 14-18 (18) longitudinal ridges. Prongs of tridents 0.065-0.093 (0.075) long. Nerve ring 0.161-0.180 (0.173) from the anterior end; excretory pore not observed. Muscular and glandular esophagus, 0.332-0.377 (0.356) and 0.441-0.490 (0.470) long, respectively. Spicules unequal and similar. The longer, $0.132-0.152(0.143)$, the shorter, $0.100-0.110(0.106)$ in length. Spicular ratio: 1: 1.31-1.40 (1: 1.35). Fourteen pairs of caudal papillae: seven pairs precloacal, two pairs ad-cloacal and five pairs post-cloacal.
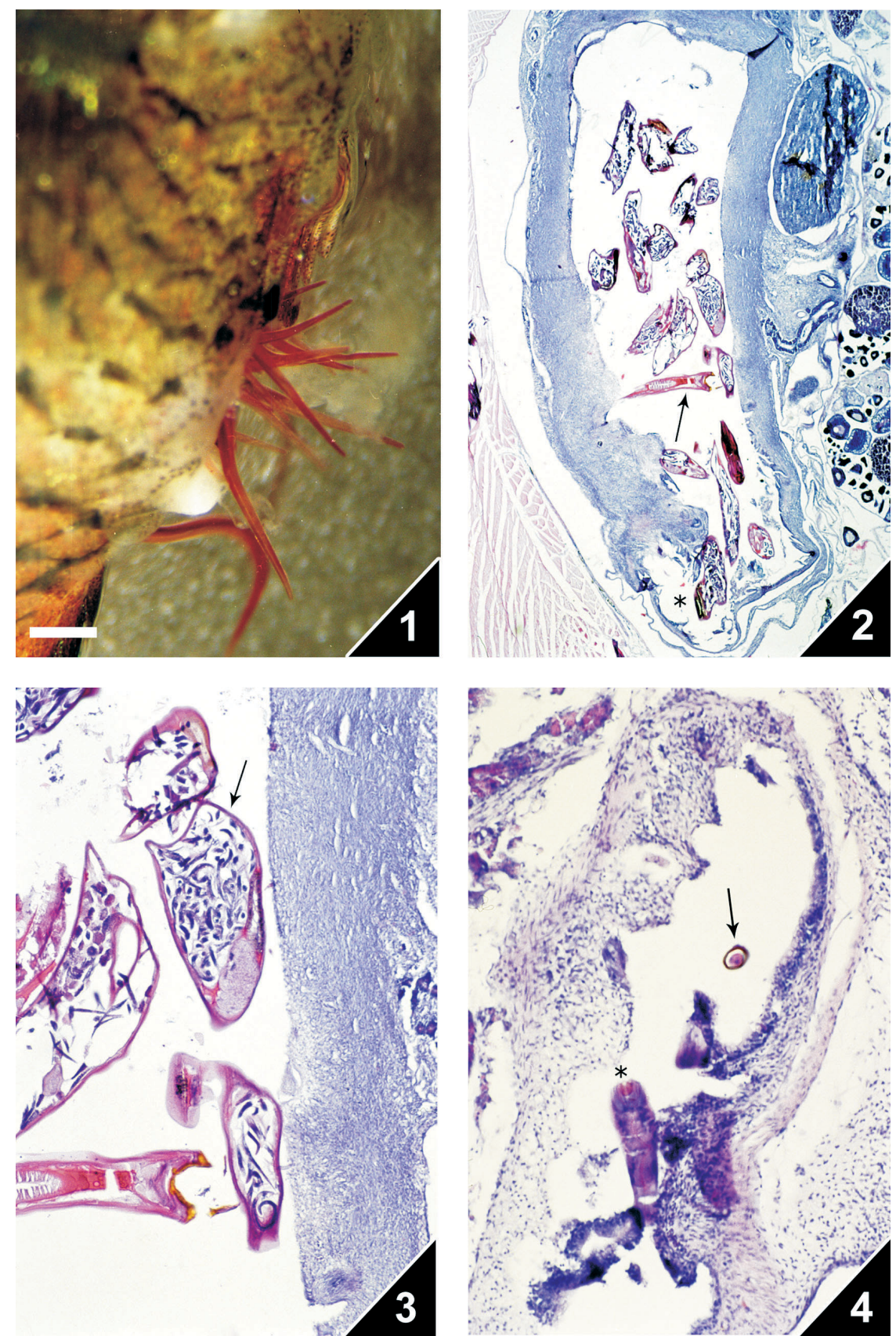

Fig. 1: live Camallanus cotti adult worms protruding from the anus of a beta fish. Bar $=0.6 \mathrm{~mm}$. Bar of Fig. 1 is common to Figs $2-4$. Fig. 2: cross-section of the rectum of a specimen of beta fish, showing adult specimens of $C$. cotti free in the intestinal lumen (arrow) or attached to the remarkably thickened wall associated to extensive areas of erosion of the mucosa (asterisk) and absence of inflammatory infiltrate. HE. Bar $=0.5 \mathrm{~mm}$. Fig. 3: cross-section (detail of Fig. 2) showing adult mature females of $C$. cotti free in the intestinal lumen, with several larvae in utero (arrow). HE. Bar $=0.3 \mathrm{~mm}$. Fig. 4: cross-section of the rectum of a guppy infected with $C$. cotti worms, showing a portion of the nematode free in the lumen (asterisk) and the buccal capsule (arrow) inserted in the intestinal mucosa. Bar $=0.7 \mathrm{~mm}$. 
Cloacal aperture $0.108-0.127$ (0.114) from the posterior extremity.

Females - Total length 7,429-9,238 (8.446), maximum width $0.293-0.366$ (0.332). Buccal capsule 0.132-0.147 (0.167) long, 0.122-0.157 (0.141) wide, including ring at base 0.078-0.093 (0.084), 0.015-0.019 (0.019). Buccal capsule with about 1419 (17) longitudinal ridges. Prongs of tridents $0.072-0.122$ (0.094) long. Nerve ring 0.240-0.249 (0.245) from the anterior end; excretory pore not observed. Muscular and glandular esophagus, $0.519-0.588(0.535)$ and $0.588-0.752$
(0.672) long, respectively. Vulvar opening 1.969-4.839 (3.596) from the anterior extremity. Ovejector directed downwards. Ovoviviparous, with eggs and larvae in utero. Eggs 0.033-0.048 (0.040) long, 0.029-0.041 (0.036) wide, larvae $0.240-0.336(0.288)$ long. Anal opening 1.087- 1.539 (1.330) from the posterior extremity.

\section{Taxonomic summary}

Hosts - Poecilia reticulata (Peters, 1859), Betta splendens (Regan, 1910); common names: guppy and beta fish, "gupi" and "peixe-beta", respectively.


Fig. 5: cross-section of the rectum of a beta fish infected with Camallanus cotti worms, showing the detail of the ridged buccal capsule inserted in the intestinal wall. HE. Bar $=0.05 \mathrm{~mm}$. Bar of Fig. 5 is common to Figs 6-8. Fig. 6: anterior portion of an adult female of $C$. cotti, ventral view. Bar $=0.05 \mathrm{~mm}$. Fig. 7: mouth of an adult female specimen of $C$. cotti, showing the sclerotized buccal ridges, apical view. Bar $=0.02 \mathrm{~mm}$. Fig. 8: buccal capsule of an adult female specimen of $C$. cotti, showing the longitudinal ridges and the lateral trident, lateral view. $\mathrm{Bar}=0.02 \mathrm{~mm}$. 

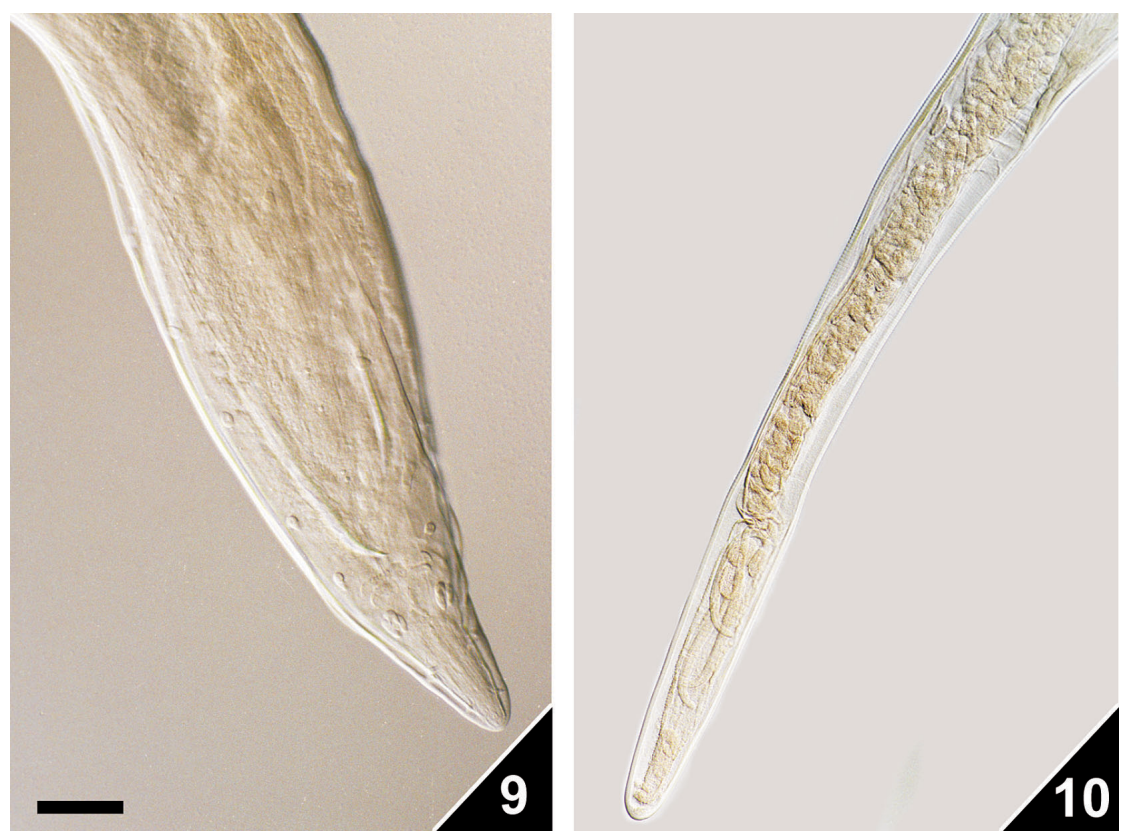

Fig. 9: posterior portion of an adult male specimen of Camallanus cotti, ventral view. Bar $=0.05 \mathrm{~mm}$. Bar of Fig. 9 is common to Fig. 10 . Fig. 10: posterior portion of an adult female specimen of $C$. cotti, lateral view. Bar $=0.1 \mathrm{~mm}$.

Site of infection - Distal portion of small intestine (rectum).

Locality of capture - Home aquarium in Niterói (22 $53^{\circ}$ 'S$\left.43^{\circ} 06^{\prime} \mathrm{W}\right)$, state of Rio de Janeiro, Brazil.

Deposited specimens - CHIOC no. 36631 a-b, 36632 a-h (whole mounts), 36637 a-b, 36638 (whole mounts with histological sections), 35442-35445 (wet material).

\section{DISCUSSION}

C. cotti was described by Fujita (1927) on the basis of nematodes recovered from four freshwater fish species captured in the lakes Biwa (three species) and Tazawa (one species) in Japan. Since, C. cotti has been considered worldwide in studies related to morphology/biology (Stumpp 1975, Moravec \& Nagasawa 1989, Rigby et al. 1997, Levsen \& Berland 2002 a,b, Levsen \& Jakobsen 2002, Moravec et al. 2003), ecology (Font \& Tate 1994, Font 1998, Vincent \& Font 2003a,b), occurrences (Kim et al. 2002, Alves et al. 2000), and fish behavior (McMinn 1990). The species was first recorded in Brazil by Alves et al. (2000), parasitizing the guppy P. reticulata, in a study related to parasite distribution and host behavior; although regarded as a potential pathogen for Brazilian fishes, aspects related to morphology and pathology of C. cotti were not presented. The pathology associated with other species of the genus Camallanus Railliet \& Henry, 1915 is known to be represented by severe intestinal lesions. According to available comparative data, specimens of C. moraveci Petter, Cassone \& France, 1974, parasitizing exotic Singaporean fishes were responsible for the death of the hosts and the induced lesions consisted of destruction of the rectal mucosa at the sites worms were attached and the suction of the submucosa into the buc- cal capsule of the parasites (Petter et al. 1974). Another pathobiologic study is related to C. oxyocephalus Ward \& Magath, 1916, infecting green sunfishes in the US. Lesions were represented by the complete destruction of the columnar epithelium of the mucosal layer. At some sites of attachment there was deep penetration into the intestinal wall, ulceration surrounded by granulomatous tissue and fibrosis, with deposition of connective tissue on the surface of ulcerated areas and among tissues grasped by the buccal capsule of the nematodes that suck blood and tissue fluids of the hosts using their extensive dentition to rasp the tissues of the gut wall (Meguid \& Eure 1996).

The observed microscopic lesions induced by $C$. cotti in the two fish species considered here, the beta fish and the guppy, were similar to those referred for $C$. moraveci by Petter et al. (1974) and for C. oxyocephalus by Meguid and Eure (1996). Nevertheless, when compared to data after the latter authors, intestinal goblet cell hyperplasia was not observed in the present investigation; conversely, the marked thickening of the intestinal wall, the small amount of glandular elements and absence of inflammatory infiltrate presently referred, were not reported by Meguid and Eure (1996). These are the first pathological findings to be reported for $C$. cotti to date and the present redescription of the species on the basis of Brazilian samples are in accordance with previous morphometric data on specimens of $C$. cotti from other countries.

\section{ACKNOWLEDGEMENTS}

To Mr Rodrigo Méxas and Mr Bruno Eschenazi from the Laboratório de Produção e Tratamento de Imagens, Instituto Oswaldo Cruz-Fiocruz, for technical support with the figures. 


\section{REFERENCES}

Alves DR, Luque JL, Paraguassú AR, Marques FA 2000. Ocorrência de Camallanus cotti (Nematoda: Camallanidae) parasitando o guppy Poecilia reticulata (Osteichthyes: Poeciliidae) no Brasil. Rev Univ Rural, Ser Ci Vida 22: 7779.

Anderson RC 1958. Méthode pour l'examen des nématodes en vue apicale. Ann Par Hum Comp 33: 171-172.

Evans BB, Lester RJG 2001. Parasites of ornamental fish imported to Australia. Bull Eur Assoc Fish Pathol 21: 51-55.

Font WF 1998. Parasites in paradise: patterns of helminth distribution in Hawaiian stream fishes. J Helminthol 72: 307333.

Font WF, Tate DC 1994. Helminth parasites of native Hawaiian freshwater fishes: an example of extreme ecological isolation. J Parasitol 80: 682-688.

Fujita T 1927. On new species of nematodes from fishes of Lake Biwa. Japan J Zool 1: 169-176.

Kim J-H, Hayward CJ, Heo G-J 2002. Nematode worm infections (Camallanus cotti, Camallanidae) in guppies (Poecilia reticulata) imported to Korea. Aquaculture 205: 231-235.

Levsen A, Berland B 2002a. The development and morphogenesis of Camallanus cotti Fujita, 1927 (Nematoda: Camallanidae), with notes on phylogeny and definitive host range. System Parasitol 53: 29-37.

Levsen A, Berland B 2002b. Post-embryonic development of Camallanus cotti (Nematoda: Camallanidae), with emphasis on growth of some taxonomically important somatic characters. Folia Parasitol 49: 231-238.

Levsen A, Jakobsen J 2002. Selection pressure towards monoxeny in Camallanus cotti (Nematoda, Camallanidae) facing an intermediate host bottlenecked situation. Parasitology 124: 625-629.
McMinn H 1990. Effects of the nematode parasite Camallanus cotti on sexual and non-sexual behaviors in the guppy (Poecilia reticulata). Amer Zool 30: 245-249.

Meguid MA, Eure HE 1996. Pathobiology associated with the spiruroid nematodes Camallanus oxycephalus and Spinitectus carolini in the intestine of green sunfish, Lepomis cyanellus. J Parasitol 82: 118-123.

Moravec F, Nagasawa K 1989. Observations on some nematodes parasitic in Japanese freshwater fishes. Folia Parasitol 36: 127-141.

Moravec F, Nie P, Wang G 2003. Some nematodes of fishes from Central China, with the redescription of Procamallanus (Spirocamallanus) fulvidraconis (Camallanidae). Folia Parasitol 50: 220-230.

Petter AJ, Cassone J, France BM 1974. Un nouveau nematode Camallanus pathogène dans des élevages de poisons exotiques. Ann Parasitol 49: 677-683.

Rigby MC, Font WF, Deardorff TL 1997. Redescription of Camallanus cotti Fujita, 1927 (Nematoda: Camallanidae from Hawaii. J Parasitol 83: 1161-1164.

Stumpp M 1975. Untersuchungen zur Morphologie und Biologie von Camallanus cotti (Fujita, 1927). Z Parasitenk 46: $277-290$.

Vincent AG, Font WF 2003a. Host specificity and population structure of two exotic helminths, Camallanus cotti (Nematoda) and Bothriocephalus acheilodnathi (Cestoda), parasitizing exotic fishes in Waianu stream, O'ahu, Hawaii. $J$ Parasitol 89: 540-544.

Vincent AG, Font WF 2003b. Seasonal and yearly population dynamics of two exotic helminths, Camallanus cotti (Nematoda) and Bothriocephalus acheilodnathi (Cestoda), parasitizing exotic fishes in Waianu stream, O'ahu, Hawaii. $J$ Parasitol 89: 756-760. 
